\title{
Associations between macronutrient intake and serum lipid profile depend on body fat in European adolescents: the Healthy Lifestyle in Europe by Nutrition in Adolescence (HELENA) study
}

\author{
Silvia Bel-Serrat ${ }^{1 *}$, Theodora Mouratidou ${ }^{1}$, Inge Huybrechts ${ }^{2,3}$, Idoia Labayen ${ }^{1,4}$,
} Magdalena Cuenca-García ${ }^{5}$, Gonzalo Palacios ${ }^{6}$, Christina Breidenassel ${ }^{6,7}$, Dénes Molnár ${ }^{8}$, Romana Roccaldo 9 , Kurt Widhalm ${ }^{10}$, Frederic Gottrand ${ }^{11}$, Anthony Kafatos ${ }^{12}$, Yannis Manios ${ }^{13}$, Krishna Vyncke ${ }^{2,14}$, Michael Sjöström ${ }^{15}$, Lars Libuda ${ }^{16}$, Sonia Gómez-Martínez ${ }^{17}$ and Luis A. Moreno ${ }^{1,18}$ on behalf of the HELENA study groupt

${ }^{1}$ Growth, Exercise, Nutrition and Development (GENUD) Research Group, Faculty of Health Sciences, University of Zaragoza, C/Pedro Cerbuna 12, 50009 Zaragoza, Spain

${ }^{2}$ Department of Public Health, Faculty of Medicine and Health Sciences, University Hospital, Ghent University, Ghent, Belgium

${ }^{3}$ Dietary Exposure Assessment Group (DEX), International Agency for Research on Cancer (IARC), Lyon, France

${ }^{4}$ Department of Nutrition and Food Science, University of the Basque Country, Vitoria, Spain

${ }^{5}$ Department of Physiology, School of Medicine, University of Granada, Granada, Spain

${ }^{6}$ Department of Health and Human Performance, Faculty of Physical Activity and Sport Sciences (INEF), Universidad Politécnica de Madrid, Madrid, Spain

${ }^{7}$ Institut für Ernährungs- und Lebensmittelwissenschaften - Humanernährung, Rheinische Friedrich-Wilhelms-Universität, Bonn, Germany

${ }^{8}$ Department of Pediatrics, University of Pécs, Pécs, Hungary

${ }^{9}$ National Research Institute for Food and Nutrition, INRAN, Rome, Italy

${ }^{10}$ Department of Pediatrics, Private Medical University Salzburg, Salzburg, Austria

${ }^{11}$ Inserm U995, Faculty of Medicine, University Lille 2, Lille, France

${ }^{12}$ Preventive Medicine and Nutrition Unit, University of Crete School of Medicine, Heraklion, Greece

${ }^{13}$ Department of Nutrition and Dietetics, Harokopio University, Athens, Greece

${ }^{14}$ Research Foundation Flanders (FWO), Brussels, Belgium

${ }^{15}$ Karolinska Institute, Huddinge, Sweden

${ }^{16}$ Research Institute of Child Nutrition Dortmund, Rheinische Friedrich-Wilhelms-Universität Bonn, Dortmund, Germany

${ }^{17}$ Institute of Food Science, Technology and Nutrition (ICTAN), Spanish National Research Council (CSIC), Madrid, Spain

${ }^{18}$ Department of Preventive Medicine, School of Medicine, University of São Paulo, São Paulo, Brazil

(Submitted 1 February 2014 - Final revision received 3 September 2014 - Accepted 8 September 2014-First published online 4 November 2014)

\section{Abstract}

The present study aimed to investigate the relationships between macronutrient intake and serum lipid profile in adolescents from eight European cities participating in the HELENA (Healthy Lifestyle in Europe by Nutrition in Adolescence) cross-sectional study (2006-7), and to assess the role of body fat-related variables in these associations. Weight, height, waist circumference, skinfold thicknesses, total cholesterol, HDL-cholesterol (HDL-C), LDL-cholesterol, TAG, apoB and apoA1 were measured in 454 adolescents (44\% boys) aged 12.5-17.5 years. Macronutrient intake $(\mathrm{g} / 4180 \mathrm{~kJ}$ per d ( $1000 \mathrm{kcal}$ per $\mathrm{d}))$ was assessed using two non-consecutive $24 \mathrm{~h}$ dietary recalls. Associations were evaluated by multi-level analysis and adjusted for sex, age, maternal education, centre, sum of four skinfolds, moderate-to-vigorous

Abbreviations: 24-HDR, $24 \mathrm{~h}$ dietary recall; HDL-C, HDL-cholesterol; HELENA, Healthy Lifestyle in Europe by Nutrition in Adolescence; LDL-C, LDLcholesterol; M:S, monosaturated:saturated fat ratio; P:S, polyunsaturated:saturated fat ratio; PA, physical activity; TC, total cholesterol; WHeR, waist:height ratio.

*Corresponding author: S. Bel-Serrat, email sbelserrat@gmail.com

† See the appendix for a full list of the HELENA study group members. 
physical activity, sedentary behaviours and diet quality index for adolescents. Carbohydrate intake was inversely associated with HDL-C ( $\beta=-0 \cdot 189, P<0 \cdot 001)$. An inverse association was found between fat intake and TAG $(\beta=-0 \cdot 319, P<0 \cdot 001)$. Associations between macronutrient intake and serum lipids varied according to adiposity levels, i.e. an inverse association between carbohydrate intake and HDL-C was only observed in those adolescents with a higher waist:height ratio. As serum lipids and excess body fat are the major markers of CVD, these findings should be considered when developing strategies to prevent the risk of CVD among adolescents.

\section{Key words: Macronutrient intake: Serum lipids: Body fat: Adolescents}

High levels of LDL-cholesterol (LDL-C) in childhood and the onset of atherosclerosis in early life ${ }^{(1)}$ could result in adult dyslipidaemias ${ }^{(2)}$, which are important cardiovascular risk factors. Therefore, evidence for factors influencing lipid profiles is necessary for public health protection and promotion.

Dietary modifications that lower atherogenic lipids and lipoproteins are effective in the prevention and treatment of CVD risk ${ }^{(3)}$. Nonetheless, the optimal dietary pattern(s) to restrain atherosclerosis progression remains to be identified ${ }^{(4)}$. For instance, a high intake of total carbohydrates has been suggested to lower HDL-cholesterol (HDL-C) concentration and to increase TAG concentration in adults ${ }^{(5)}$, and a proteinrich diet low in saturated fat has been shown to significantly decrease the concentrations of LDL-C, TAG and total cholesterol (TC) in comparison to a carbohydrate-rich diet and a diet rich in unsaturated fat ${ }^{(6)}$. However, findings about the role of dietary fat, mainly that of saturated fat, in CVD risk are still controversial ${ }^{(7)}$ because of individual variability in serum lipid response to changes in dietary saturated fat and cholesterol ${ }^{(3)}$. Additionally, obesity has been reported to strongly affect serum lipid response to diet ${ }^{(3)}$, making obese individuals less responsive to dietary interventions aimed to improve serum lipid profile.

Adolescence is a key period in life because of the growth spurt and sexual maturation that take place; therefore, having a healthy diet is essential to achieve optimal development and to prevent the appearance of chronic diseases later in life ${ }^{(8)}$. Furthermore, associations between macronutrient intake and serum lipids have mainly been investigated among adults, and there is a lack of the literature addressing this topic in adolescents. As these associations have not been examined yet among adolescents, we hypothesised that macronutrient intake was associated with serum lipids in a sample of healthy European adolescents and that body adiposity may exert a key role in this association. Therefore, the aims of the present study were (1) to investigate the relationships between macronutrient intake and serum lipid profile in European adolescents and (2) to assess the role of body fat-related variables in these associations.

\section{Materials and methods}

The present study sample was derived from the cross-sectional multi-centre HELENA (Healthy Lifestyle in Europe by Nutrition in Adolescence) study ( $n$ 3528) carried out in adolescents (12.5-17.5 years) between 2006 and 2007 in ten European cities (Athens and Heraklion in Greece, Dortmund in
Germany, Ghent in Belgium, Lille in France, Pécs in Hungary, Rome in Italy, Stockholm in Sweden, Vienna in Austria and Zaragoza in Spain). General HELENA procedures, characteristics and inclusion criteria can be found elsewhere ${ }^{(9,10)}$. The present study was conducted according to the guidelines laid down in the Declaration of Helsinki, and all procedures involving human subjects were approved by the local ethical committee at each study centre ${ }^{(11)}$. Written informed consent was obtained from all adolescents and their parents.

Participants with complete data on TAG, TC, HDL-C, LDL-C, apoA1, apoB and two $24 \mathrm{~h}$ dietary recalls (24-HDR) were included ( $n$ 454; 44\% boys). Decreases from the original sample size are partially explained by the fact that blood samples were randomly drawn only in one-third of the HELENA participants and partially from the fact that Heraklion and Pécs were excluded from the 24-HDR analyses due to logistical reasons; therefore, eight out of the ten study centres were included in the 24-HDR analyses, resulting in a sample size decrease. Excluded participants ( $n$ 3074) were significantly $(P<0.05)$ older, heavier and had a higher mean BMI than those included in the present study (data not shown).

\section{Macronutrient intake}

Dietary intake was assessed using a self-administered computer-based tool called HELENA-DIAT (Dietary Assessment Tool), based on the previously developed software Young Adolescents' Nutrition Assessment on Computer (YANA-C) that was shown to be appropriate in assessing dietary information of European adolescents ${ }^{(12,13)}$. The software consists of a single, structured 24-HDR according to six meal occasions. Adolescents were asked to recall all food and drinks consumed the previous day. Within a time span of 2 weeks, two non-consecutive 24-HDR were obtained from each participant during school time and assisted by fieldworkers. Therefore, no information on Fridays and Saturdays was collected.

The German Food Code and Nutrition Data Base (Bundeslebensmittelschlüssel, BLS version II.3.1) ${ }^{(14)}$ was used to calculate energy and nutrient intakes. Usual food and nutrient intakes were estimated by the multiple source method in order to account for within-person variability ${ }^{(15)}$. Energy intake was estimated in $\mathrm{kJ} / \mathrm{d}$ and macronutrient intake (fat, protein and carbohydrate) in $\mathrm{g} / \mathrm{d}$. Subsequently, intakes of each macronutrient were divided by energy intake and are expressed as $\mathrm{g} / 4180 \mathrm{~kJ}$ per $\mathrm{d}(1000 \mathrm{kcal}$ per d) to account for total energy intake ${ }^{(16)}$. Additionally, the monounsaturated:saturated fat ratio (M:S), the polyunsaturated: 
saturated fat ratio (P:S) and the cholesterol-saturated fat index (CSI) were computed as follows ${ }^{(17)}$ :

$$
\mathrm{CSI}=(1.01 \times \mathrm{g} \text { saturated fat })+(0.05 \times \mathrm{mg} \text { cholesterol }) .
$$

\section{Diet Quality Index for Adolescents}

A previously validated Diet Quality Index for Adolescents $(D Q I-A)^{(18)}$ was used to adjust for all dietary factors simultaneously. The technical aspects regarding the development of the DQI-A have been published elsewhere ${ }^{(18)}$

\section{Physical examinations}

All anthropometric measurements were taken following a standardised protocol described elsewhere ${ }^{(19)}$. Weight and height were measured in underwear and barefoot using an electronic scale (Type SECA 861) and a stadiometer (Type SECA 225). BMI was calculated as body weight (in kg) divided by the square of height (in $\mathrm{m}$ ) and was categorised as described by Cole et al. ${ }^{(20,21)}$. Skinfold thicknesses were measured with a calliper (Holtain Ltd) in triplicate on the left side at the biceps, triceps, subscapular and suprailiac sites. Waist circumference was measured at the midpoint between the lowest rib and the iliac crest using an anthropometric tape (SECA 200). The waist:height ratio (WHeR) was calculated.

\section{Blood sampling}

Blood sampling procedures have been described elsewhere ${ }^{(22)}$. Briefly, blood samples were drawn after a $10 \mathrm{~h}$ overnight fast and analysed in centralised laboratories. Serum TAG, TC, HDL-C, TAG and LDL-C concentrations were measured on a Dimension RxL clinical chemistry system (Dade Behring) with enzymatic methods using the manufacturer's reagents and instructions. ApoB and apoA1 were measured in an immunochemical reaction with a BN II analyser (Dade Behring), according to the manufacturer's instructions. The technique consists of the following: the proteins contained in the serum sample form immune complexes with specific antibodies. These complexes scatter a beam of light when it passes through the sample. As the intensity of the scattered light is proportional to the concentration of the relevant protein in the sample, the result is evaluated by comparison with a standard of known concentration. Quantitative evaluation was made by comparison with standard concentrations. Intra-assay $\mathrm{CV}$ for all blood variables were $<3.9 \%$, and interassay $\mathrm{CV}$ were $<4.3 \%$. The TC:HDL-C and the apoB:apoA1 ratios were computed.

\section{Education}

Maternal education was used as a proxy of socio-economic status and was assessed via a questionnaire according to the following four categories: (1) lower education; (2) lower secondary education; (3) higher secondary education; (4) higher education/university degree.

\section{Sedentary behaviours}

Average time spent in two sedentary behaviours (television viewing and playing with videogames) was estimated by means of a self-administered questionnaire that has been previously found to demonstrate good reliability ${ }^{(23)}$.

\section{Physical activity}

Physical activity (PA) was objectively measured by uniaxial accelerometers during seven consecutive days (Actigraph MTI, model GT1M; Manufacturing Technology, Inc. ${ }^{(24)}$. At least $3 \mathrm{~d}$ of recording, with a minimum of $8 \mathrm{~h}$ registration per $\mathrm{d}$, was set as an inclusion criterion. The time sampling interval was set at $15 \mathrm{~s}$. The time spent in moderate-tovigorous PA ( $>3$ metabolic equivalents) was calculated on the basis of the following cut-off point: $\geq 2000$ counts/min for moderate-to-vigorous $\mathrm{PA}^{(24,25)}$.

\section{Statistical analysis}

The normality of all variables was checked and non-normally distributed variables (TAG, TC, HDL-C, LDL-C, TC:HDL-C ratio, apoB:apoA1 ratio, fat intake and $\mathrm{P}: \mathrm{S}$ ratio) were log transformed before the analysis. Normality for the CSI was reached by using the power of 2 . The M:S ratio was converted to $1 /(\mathrm{M}: \mathrm{S})$ Differences across the groups were tested by means of the independent-samples $t$ test for normally distributed variables and the Mann-Whitney $U$ test for non-normally distributed variables. The $\chi^{2}$ test was applied for categorical variables.

Multi-level linear regression analyses were performed to investigate the associations between the intakes of macronutrients (independent variables) and plasma lipid concentrations (dependent variables). As no interaction by sex was found, the analyses were conducted with boys and girls combined. Study centre was included as the random intercept. Sex, age, maternal education, sum of four skinfolds, moderate-to-vigorous PA, sedentary behaviours and DQI-A were entered as covariates. Collinearity tests showed no collinearity among the covariates.

Since serum lipid profile has previously been associated with body fat in the HELENA adolescents ${ }^{(26)}$ and excess adiposity has been shown to have an influence on serum lipid response to diet $^{(3)}$, participants were categorised into low and high body fat content according to three body fat indicators, i.e. $z$-score of BMI and sum of skinfolds as the measures of general body fatness, and the WHeR as an indicator of central adiposity. These cut-offs were calculated specifically by sex and by 1-year groups (12.5-13.49, 13.5-14.49, 14.5-15.49, 15.5-16.49 and 16.5-17.5) based on the median of each subgroup. Multi-level linear regression analyses on the associations between macronutrient intake and serum lipid concentrations were performed separately for each group of low/high body fat indicator and adjusted for potential confounders, i.e. sex, age, maternal education, sum of four skinfolds, moderate-to-vigorous PA, sedentary behaviours and DQI-A, where study centre was entered as the random intercept. No collinearity was observed among 
the covariates. The level of statistical significance was controlled for multiple testing $(0 \cdot 05 /$ number of tests $=0.05 /$ $8=0.006)$; therefore, statistical significance was considered at $P \leq 0.006$. Multi-level linear regression analyses were re-run by using tertiles of protein, carbohydrate and fat intake. Bonferroni correction was used for the post boc multiple comparison test, and statistical significance was set at $P<0 \cdot 05$. Statistical analysis was performed using the statistical software package STATA version 12.0 (Stata Corporation).

\section{Results}

The main characteristics of the study sample are shown in Table 1. Table 2 presents the means and medians of dietary intake and blood lipid levels according to high/low body WHeR, i.e. above or below the sex- and age-specific median-based cut-offs of the WHeR. Adolescents in the high-WHeR group showed significantly higher protein intake $(\mathrm{g} / 4180 \mathrm{~kJ})$ and percentage of protein intake, M:S ratio, TAG, TC:HDL-C ratio and apoB:apoA1 ratio and lower total energy intake than adolescents in the low-WHeR group.

The associations between macronutrient intake $(\mathrm{g} / 4180 \mathrm{~kJ})$ and serum lipid profile are shown in Table 3. Carbohydrate intake was inversely associated with HDL-C $(P=0 \cdot 001)$, and a trend towards significance $(P=0 \cdot 010)$ was observed for apoA1. Inverse associations were found between fat intake and TAG $(P<0.001)$ and TC:HDL-C ratio $(P=0.005)$. LDL-C, apoB and apoB:apoA1 ratio were not significantly associated,

Table 1. Descriptive characteristics of the study sample stratified by sex (Mean values and standard deviations; percentages; medians and 25th-75th percentiles)

\begin{tabular}{|c|c|c|c|c|c|}
\hline & \multicolumn{2}{|c|}{ Boys (n 200) } & \multicolumn{2}{|c|}{ Girls (n 254) } & \multirow[b]{2}{*}{$P$} \\
\hline & Mean & SD & Mean & SD & \\
\hline Age (years) & 14 & $1 \cdot 2$ & 14 & $1 \cdot 2$ & 0.085 \\
\hline Weight (kg) & 59 & 13 & 56 & 11 & $<0.001$ \\
\hline Height (cm) & 170 & $9 \cdot 8$ & 162 & $7 \cdot 5$ & $<0.001$ \\
\hline BMI $\left(\mathrm{kg} / \mathrm{m}^{2}\right)$ & 20 & 3.4 & 21 & 3.5 & 0.097 \\
\hline Underweight (\%)† & & $8 \cdot 2$ & & $6 \cdot 6$ & - \\
\hline Normal weight (\%) & & 75 & & 73 & - \\
\hline Overweight (\%) & & 10 & & 16 & - \\
\hline Obese $(\%)$ & & $6 \cdot 7$ & & 4.5 & - \\
\hline Maternal education (\%) & & & & & $0.035 \ddagger$ \\
\hline Lower education & & $6 \cdot 2$ & & 10 & - \\
\hline Lower secondary education & & 18 & & 23 & - \\
\hline Higher secondary education & & 30 & & 34 & - \\
\hline Higher education/University degree & & 46 & & 33 & - \\
\hline ApoA1 $(g / l)$ & 1.48 & 0.01 & 1.55 & 0.01 & $<0.001$ \\
\hline \multirow[t]{2}{*}{ ApoB $(g / l)$} & 0.61 & 0.01 & 0.67 & 0.01 & $<0.001$ \\
\hline & Median & 25th-75th percentile & Median & 25th-75th percentile & \\
\hline Sum of four skinfolds (mm) & 34 & $26-52$ & 54 & $40-75$ & $<0.001 \xi$ \\
\hline Waist:height ratio & 0.42 & $0.40-0.44$ & 0.43 & $0.40-0.47$ & $0.005 \S$ \\
\hline MVPA $(\mathrm{min} / \mathrm{d})$ & 64 & $50-82$ & 48 & $34-60$ & $<0.001 \xi$ \\
\hline Sedentary behaviours (min/d) & 133 & $77-209$ & 107 & $65-167$ & $<0.001 \S$ \\
\hline DQI-A & 51 & $37-62$ & 55 & $44-65$ & $<0.001 \xi$ \\
\hline \multicolumn{6}{|l|}{ Total energy intake } \\
\hline $\mathrm{kJ} / \mathrm{d}$ & 10263 & $8506-12560$ & 7665 & $6330-9243$ & $<0.001 \S$ \\
\hline $\mathrm{kcal} / \mathrm{d}$ & 2453 & 2033-3002 & 1832 & $1513-2209$ & $<0.001 \xi$ \\
\hline Protein intake $(\mathrm{g} / 4180 \mathrm{~kJ})$ & 40 & $35-45$ & 40 & $35-46$ & 0.881 \\
\hline Carbohydrate intake (g/4180 kJ) & 120 & $112-132$ & 123 & $112-135$ & 0.193 \\
\hline Fat intake $(\mathrm{g} / 4180 \mathrm{~kJ})$ & 41 & $36-47$ & 42 & $34-48$ & 0.594 \\
\hline Saturated fat intake $(\mathrm{g} / 4180 \mathrm{~kJ})$ & 16 & $13-17$ & 15 & $14-17$ & 0.417 \\
\hline Monounsaturated fat intake $(\mathrm{g} / 4180 \mathrm{~kJ})$ & 14 & $12-15$ & 13 & $12-15$ & 0.114 \\
\hline Polyunsaturated fat intake $(\mathrm{g} / 4180 \mathrm{~kJ})$ & 5 & $4-6$ & 5 & $4-6$ & 0.594 \\
\hline Monounsaturated:saturated ratio & 0.86 & $0.78-0.99$ & 0.86 & $0.77-0.99$ & 0.966 \\
\hline Polyunsaturated:saturated ratio & 0.32 & $0.26-0.41$ & 0.33 & $0.27-0.42$ & 0.468 \\
\hline Cholesterol-saturated fat index & 23 & $21-26$ & 24 & $21-27$ & 0.267 \\
\hline TAG $(\mathrm{mmol} / \mathrm{l})$ & 0.64 & $0.49-0.87$ & 0.71 & $0.54-0.95$ & $<0.001 \S$ \\
\hline $\mathrm{TC}(\mathrm{mmol} / \mathrm{l})$ & 3.99 & $3.57-4.35$ & 4.33 & $3.83-4.77$ & $<0.001 \S$ \\
\hline HDL-C $(\mathrm{mmol} / \mathrm{l})$ & 1.40 & $1.22-1.53$ & 1.45 & $1.30-1.66$ & $<0.001 \xi$ \\
\hline LDL-C $(\mathrm{mmol} / \mathrm{l})$ & 2.33 & $1.99-2.59$ & $2 \cdot 51$ & $2.07-2.95$ & $<0.001$ \\
\hline TC:HDL-C & $2 \cdot 8$ & $2 \cdot 5-3 \cdot 2$ & 2.9 & $2 \cdot 5-3.4$ & 0.340 \\
\hline ApoB:apoA1 & 0.43 & $0.33-0.48$ & 0.42 & $0.35-0.50$ & 0.169 \\
\hline
\end{tabular}


Table 2. Dietary characteristics and serum lipid parameters stratified by high $v$. low waist:height ratioł (Mean values and standard deviations; medians and 25th-75th percentiles)

\begin{tabular}{|c|c|c|c|c|}
\hline & \multicolumn{4}{|c|}{ Waist:height ratio } \\
\hline & \multicolumn{2}{|r|}{ High (n 217) } & \multicolumn{2}{|r|}{ Low (n 218) } \\
\hline & Median & 25th-75th percentile & Median & 25th-75th percentile \\
\hline \multicolumn{5}{|l|}{ ApoA1 (g/l) } \\
\hline Mean & & $1.49^{*}$ & & 1.55 \\
\hline SD & & 0.21 & & 0.22 \\
\hline \multicolumn{5}{|l|}{ ApoB (g/l) } \\
\hline Mean & & 0.65 & & 0.64 \\
\hline SD & & 0.16 & & 0.15 \\
\hline Protein intake $(\mathrm{g})$ & $79 \dagger$ & $63-103$ & 87 & $70-105$ \\
\hline Protein intake $(\mathrm{g} / 4180 \mathrm{~kJ})$ & $41 \dagger$ & $36-46$ & 38 & $34-43$ \\
\hline Protein intake (\% energy) & $16 \dagger$ & $14-19$ & 15 & $14-17$ \\
\hline Carbohydrate intake $(\mathrm{g})$ & $235 \dagger$ & $190-292$ & 267 & $220-347$ \\
\hline Carbohydrate intake (g/4180 kJ) & 121 & $112-135$ & 124 & $112-134$ \\
\hline Carbohydrate intake (\% energy) & 48 & $45-54$ & 50 & $45-53$ \\
\hline Fat intake $(\mathrm{g})$ & 83 & $60-104$ & 92 & $67-118$ \\
\hline Fat intake $(\mathrm{g} / 4180 \mathrm{~kJ})$ & 42 & $36-49$ & 41 & $34-47$ \\
\hline Fat intake (\% energy) & 38 & $32-44$ & 37 & $31-42$ \\
\hline Saturated fat intake $(\mathrm{g} / 4180 \mathrm{~kJ})$ & 15 & $13-17$ & 16 & $14-17$ \\
\hline Monounsaturated fat intake $(\mathrm{g} / 4180 \mathrm{~kJ})$ & $14 \dagger$ & $12-16$ & 13 & $11-15$ \\
\hline Polyunsaturated fat intake $(\mathrm{g} / 4180 \mathrm{~kJ})$ & 5 & $4-6$ & 5 & $4-6$ \\
\hline Monounsaturated:saturated ratio & $0.89 \dagger$ & $0.80-1.01$ & 0.84 & $0.74-0.97$ \\
\hline Polyunsaturated:saturated ratio & 0.33 & $0.28-0.41$ & 0.33 & $0.26-0.42$ \\
\hline Cholesterol-saturated fat index & 24 & $21-26$ & 23 & $21-26$ \\
\hline TAG (mmol/l) & $0.71 \dagger$ & $0.52-1.03$ & 0.66 & $0.52-0.86$ \\
\hline $\mathrm{TC}(\mathrm{mmol} / \mathrm{l})$ & $4 \cdot 20$ & $3.65-4.58$ & $4 \cdot 17$ & $3 \cdot 70-4.61$ \\
\hline HDL-C (mmol/l) & 1.40 & $1.24-1.55$ & 1.45 & $1.30-1.68$ \\
\hline LDL-C (mmol/l) & 2.43 & $2 \cdot 07-2 \cdot 82$ & $2 \cdot 41$ & $2.05-2.77$ \\
\hline TC:HDL-C & $3.0 \dagger$ & $2 \cdot 6-3 \cdot 4$ & $2 \cdot 8$ & $2 \cdot 4-3 \cdot 2$ \\
\hline ApoB:apoA1 & $0.44 t$ & $0.36-0.50$ & 0.41 & $0.33-0.50$ \\
\hline
\end{tabular}

TC, total cholesterol; HDL-C, HDL-cholesterol; LDL-C, LDL-cholesterol.

* Mean value was significantly different from that of adolescents in the low-adiposity waist:height ratio group $(P<0.05$; independent-samples $t$ test).

† Median value was significantly different from that of adolescents in the low-adiposity waist:height ratio group $(P<0.05$; Mann-Whitney $U$ test).

$\ddagger$ High- and low-waist:height ratio groups were defined by means of sex- and age-specific medians.

but an inverse trend towards significance was observed. In addition, a positive trend towards significance was found between fat intake and HDL-C $(P=0.047)$. Protein intake was not significantly associated with TAG, but an inverse trend towards significance was observed $(P=0 \cdot 027)$.

Analyses were conducted for the three body fat indicators; however, the results have been focused on only one measure of adiposity, specifically central adiposity, to ease its interpretation. Table 4 presents the associations between macronutrient intake and blood lipid profile for the low and high WHeR. Carbohydrate intake was inversely associated $(P=0 \cdot 001)$ with HDL-C in adolescents with the high WHeR and a negative trend was found for apoA1 $(P=0.043)$, but not in those with the low WHeR. A positive trend towards significance $(P=0.011)$ was observed between the intake of carbohydrate and TAG concentration only in those adolescents within the high WHeR group. An inverse trend between fat intake and TAG $(P=0.008)$ and TC:HDL-C ratio $(P=0.044)$ was found in adolescents with the high WHeR. Although not significantly associated, inverse trends between protein intake and TAG $(P=0.021)$ and LDL-C $(P=0.049)$ concentrations were observed only in adolescents with the high WHeR. The results were consistent with the other measures of adiposity, namely sum of four skinfolds and $z$-score of BMI (data not shown).

Fig. 1 shows the means of TAG, TC, HDL-C and LDL-C concentrations by tertiles of fat intake in adolescents with the high and low WHeR. Overall, adolescents with the high WHeR in the lower tertile of fat intake (tertile 1) showed clinically adverse values of serum lipid concentrations, i.e. higher TAG, TC and LDL-C concentrations, and lower HDL-C concentration, compared with those in the higher tertile of fat intake (tertile 3). Within the upper tertile of fat intake, adolescents with the high WHeR had better values of blood parameters, whereas slight differences were observed across the tertiles of fat intake in adolescents with lower central adiposity levels. Indeed, adolescents with the high WHeR (Fig. 1(a)) in the lowest tertile of fat intake showed significantly higher TAG concentrations than those in the upper tertile of fat intake $(P<0.05)$. Furthermore, a significant interaction $(P<0.05)$ was observed between fat intake and WHeR for TAG (Fig. 1(a)). In contrast, adolescents with high adiposity levels, i.e. high WHeR, in the upper tertile of carbohydrate intake showed significantly higher TAG levels than those in the lower tertile of carbohydrate intake $(P<0.05$, data not shown). No significant differences were observed across tertiles of protein intake (data not shown). 
Identical findings across the tertiles of fat intake were observed in adolescents with the high/low sum of skinfolds.

\section{Discussion}

The present study examined the associations between energy-adjusted macronutrient intake and serum lipid profile, as well as the potential role that body adiposity may exert on these associations among healthy European adolescents. Overall, the results suggested that dietary fat has a beneficial role in serum lipid levels by lowering serum TAG levels and TC:HDL-C ratio, whereas carbohydrate intake was adversely associated with lipid profile by decreasing serum HDL-C concentrations. These above-mentioned associations varied according to the body fat status of adolescents, i.e. significant associations and trends towards significance between intakes of fat and carbohydrate and blood lipids were observed mainly among adolescents in the high-body fat group. To the best of our knowledge, the present study is a novel study as it is the first to address such relationships among adolescents.

The associations between carbohydrate intake and HDL-C add further evidence to the complex and adverse role that dietary carbohydrates appear to play in serum lipid profile ${ }^{(5)}$. Indeed, a high intake of total carbohydrate is also associated with lower HDL-C and higher TAG concentrations in adults $^{(5)}$ and children ${ }^{(27)}$. Nevertheless, it is important to take into account that we did not discriminate among the types of carbohydrates, i.e. simple and complex carbohydrates, meaning that the observed associations may have differed among the subtypes of carbohydrates. However, it is known that serum lipid levels are controlled not only by dietary carbohydrates but also by dietary proteins ${ }^{(28)}$. Although available data addressing the associations between dietary protein intake and serum lipids are still limited, vegetal sources of protein per se have been shown to lower plasma cholesterol concentrations $^{(29)}$. Furthermore, Appel et al. ${ }^{(6)}$ observed that a healthy diet, rich in protein and low in saturated fat, significantly decreased the concentrations of LDL-C, TAG and TC among adults compared with a carbohydrate-rich diet and a diet rich in unsaturated fat. The inverse association that we found between protein intake and TAG concentration is partially in concordance with these findings.

The role of fat intake in serum lipid levels differs according to the type of fat consumed. Indeed, the fatty acid profile of the diet seems to be the major determinant of serum cholesterol concentrations ${ }^{(30)}$. The findings from a follow-up study $^{(31)}$ have suggested that replacing dietary saturated fat with polyunsaturated fat rather than with monounsaturated fat or carbohydrates protects middle-aged and older men and women from the risk of CHD. Other studies have observed that replacement of dietary saturated fat with polyunsaturated fat, monounsaturated fat and/or carbohydrates reduces LDL-C concentration ${ }^{(32,33)}$. PUFA intake decreases LDL-C concentration ${ }^{(30)}$ and MUFA intake decreases the TC:HDL-C ratio when isoenergetically compared with SFA intake ${ }^{(34)}$. Monounsaturated fat-rich diets have been shown to have comparable effects on serum lipid concentrations 
Table 4. Multi-level regression analysis addressing the associations between macronutrient intake and serum lipid profile categorised by high $v$. low waist:height ratio $(\mathrm{WHeR}) \ddagger$

( $\beta$-Coefficients and $95 \%$ confidence intervals)

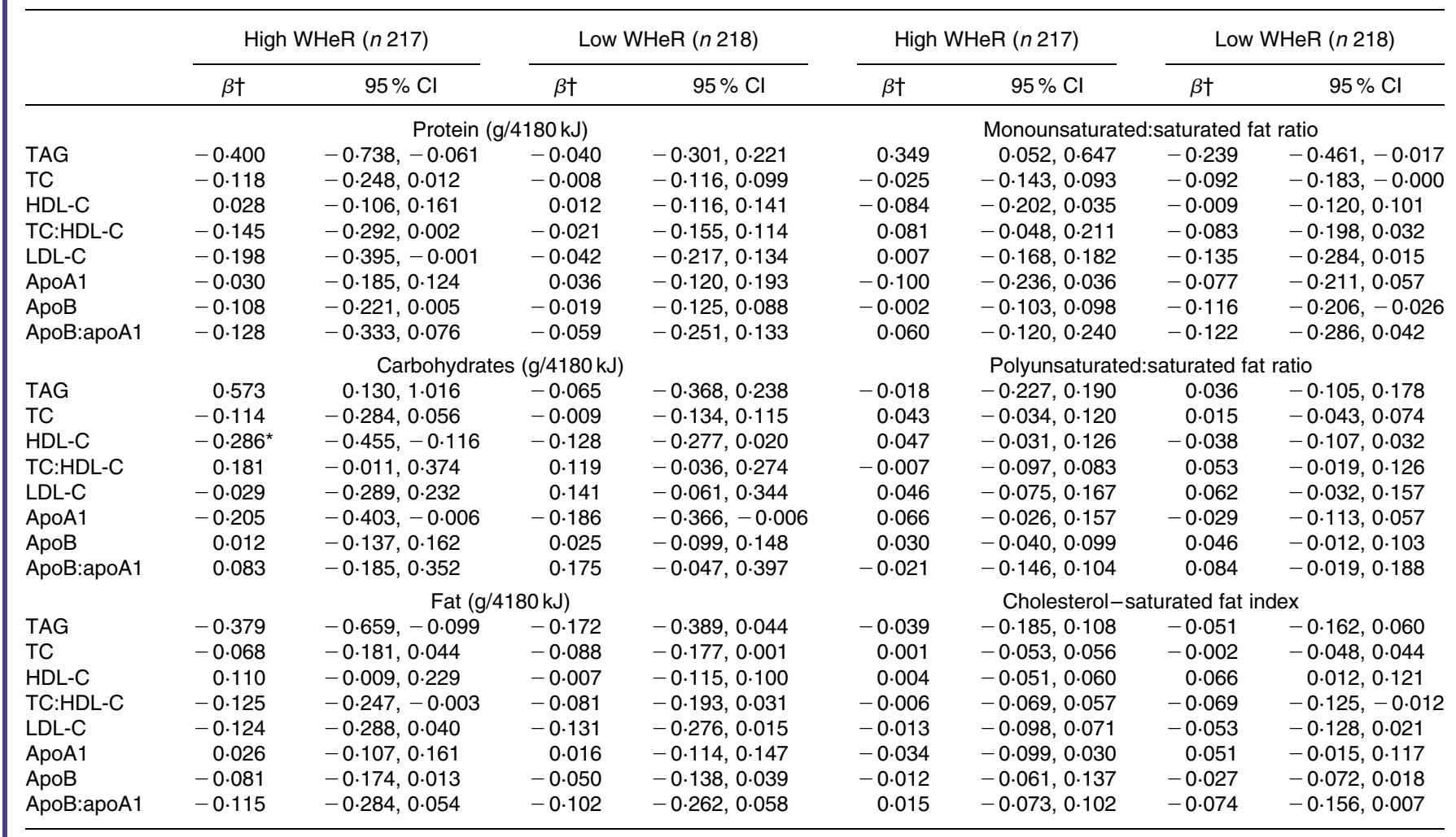

TC, total cholesterol; HDL-C, HDL-cholesterol; LDL-C, LDL-cholesterol.

${ }^{*} P<0.006$ (Bonferroni correction).

†Adjusted by sex, age, study centre, maternal education, moderate-to-vigorous physical activity, sedentary behaviours and diet quality index for adolescents.

$\ddagger$ High and low waist:height ratio was defined by means of sex- and age-specific medians.

with diets rich in PUFA, although they tend to reduce TAG concentration less, but elevate HDL-C concentration more than PUFA-rich diets ${ }^{(34)}$. Accordingly, further analysis carried out in the present study sample showed a positive association between monounsaturated fat intake and HDL-C and apoA1. For this reason, the inverse association observed between total fat intake and TAG and TC:HDL-C ratio could be partially explained by the presence of polyunsaturated and monounsaturated fat, although no significant associations were observed between the M:S and P:S ratios and serum lipids. However, adolescents with higher levels of adiposity showed significantly higher intakes of monounsaturated fat and a higher $\mathrm{M}: S$ ratio. The results from a recent meta-regression ${ }^{(35)}$ have revealed that increases in HDL-C concentrations are associated with higher amounts of total fat mainly derived from monounsaturated fat in high-fat diets, whereas higher intakes of carbohydrates are associated with increases in TAG levels. Lyu et al. $^{(36)}$ also found a positive association between total fat intake and apoA1 in both men and women. Such findings could denote a positive role of dietary fat in different fractions of serum lipids and are consistent with several experimental studies that observed unfavourable effects of low-fat diets on HDL-C, TC:HDL-C ratio and postprandial TAG concentrations in women when compared with men ${ }^{(37-40)}$.
Focusing on saturated fat, a meta-analysis of prospective cohort studies ${ }^{(7)}$ did not find significant evidence to conclude that dietary saturated fat intake was associated with the increased risk of CVD. However, these findings should be interpreted with caution as, according to Kromhout et al. ${ }^{(41)}$, existing sources of error in both dietary exposure and effect measure might have attenuated the correlation between dietary saturated fat intake and serum cholesterol concentration, leading to a correlation close to zero. Nevertheless, Mozaffarian et al. ${ }^{(4)}$ observed that a greater intake of saturated fat was associated with higher HDL-C and apoA1 concentrations, and lower TAG concentration and TC:HDL-C ratio in postmenopausal women. It seems that not all SFA have identical effects on serum cholesterol levels ${ }^{(30)}$, suggesting that the effects of saturated fat intake on serum lipids vary according to the specific SFA consumed ${ }^{(42)}$. The findings from a study conducted among Swedish adolescents revealed significant inverse associations between the dietary content of SFA with a chain length of four to fifteen carbon atoms and the serum concentrations of $\mathrm{TC}$ and $\mathrm{apoB}^{(43)}$. A meta-analysis of controlled feeding experiments has shown that SFA with twelve, fourteen, sixteen and eighteen carbon atoms increased the concentration of HDL-C when they isoenergetically replaced carbohydrate ${ }^{(44)}$. It should be noted that the increases in HDL-C concentration were greater as the chain 

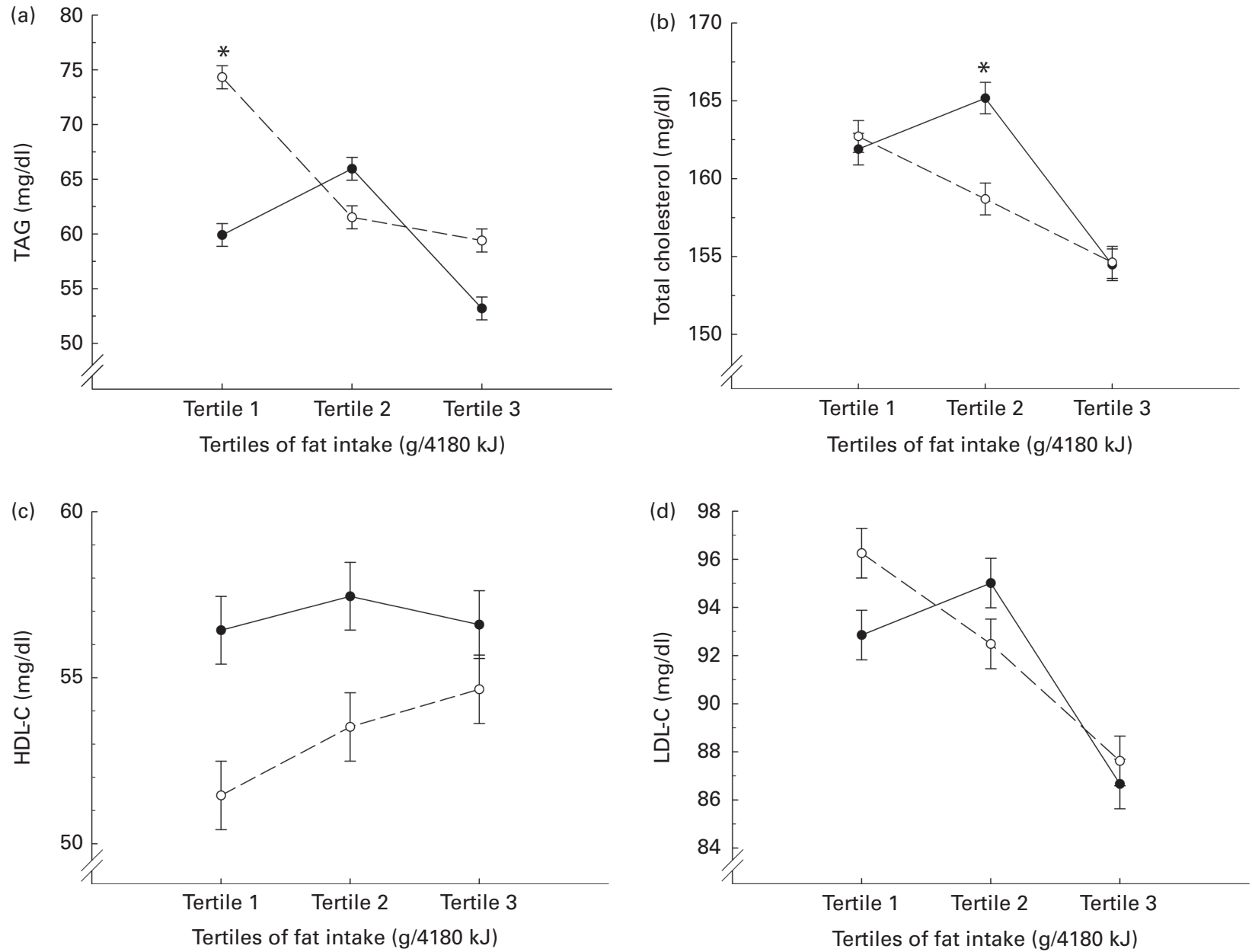

Fig. 1. TAG (a), total cholesterol (b), HDL-cholesterol (HDL-C) (c) and LDL-cholesterol (LDL-C) (d) by tertiles of fat intake for high (-O-) and low (- $\bullet-)$ waist: height ratio (WHeR) after adjustment for covariates: age; sex; study centre; socio-economic status; moderate-to-vigorous physical activity; sedentary behaviours; diet quality index for adolescents. Values are means, with their standard errors represented by vertical bars. To convert TAG in mg/dl to mmol/l, multiply by 0.0113 . To convert cholesterol in $\mathrm{mg} / \mathrm{dl}$ to $\mathrm{mmol} / \mathrm{l}$, multiply by 0.0259 . * Mean value was significantly different from that of adolescents in the higher tertile of fat intake $(P<0.05$; Bonferroni's correction for post hoc multiple comparisons). Unlogged values are shown for easier interpretability. Median fat intake: tertile 1 - $32.1 \mathrm{~g} / 4180 \mathrm{~kJ}(1000 \mathrm{kcal}$ ) (low WHeR), $33.6 \mathrm{~g} / 4180 \mathrm{~kJ}$ (1000 kcal) (high WHeR); tertile $2-40.8 \mathrm{~g} / 4180 \mathrm{~kJ}$ (1000 kcal) (low WHeR), $41.9 \mathrm{~g} / 4180 \mathrm{~kJ}(1000 \mathrm{kcal})$ (high WHeR); tertile $3-50.0 \mathrm{~g} / 4180 \mathrm{~kJ}$ (1000 kcal) (low WHeR), $51.4 \mathrm{~g} / 4180 \mathrm{~kJ}(1000 \mathrm{kcal})$ (high WHeR).

length decreased. Overall, the TC:HDL-C ratio was not significantly affected by SFA with fourteen, sixteen and eighteen carbon atoms; however, it significantly decreased when SFA with twelve carbon atoms replaced carbohydrate ${ }^{(44)}$. In addition to the effect of the chain length, there may also be an effect of the source of saturated fat on TC and HDL-C concentrations. For example, despite its animal origin, milk fat elevates serum HDL-C concentration ${ }^{(45)}$. In addition, the unique position of SFA in milk fat, which is typically the position of unsaturated fatty acids in plant oils, may also affect postprandial metabolism, leading to the prevention of elevated serum TC and TAG concentrations ${ }^{(45)}$

Variability in lipid response to diet is affected by numerous factors, but excess adiposity seems to be one of the strongest factors ${ }^{(3)}$. Our findings showed that associations between macronutrient intake and serum lipids varied by body fat status in the present study sample of healthy adolescents regardless of the definition employed, i.e. general body fatness ( $z$-score of BMI and sum of skinfolds) or central body fat (WHeR). Previous reports have pointed out that adiposity plays a key role in these associations among adults ${ }^{(36,46)}$. Lyu et al. ${ }^{(36)}$ observed that general body fatness, but also body fat distribution, might exert different effects on HDL-C subclasses. Obese individuals have shown lower responses to dietary interventions focused on improving their serum lipid profile ${ }^{(3)}$. Indeed, Denke $e t$ al. ${ }^{(47)}$ found that the response to a LDL-C-lowering diet was lower in obese participants than in those with a lower BMI $\left(<21 \mathrm{~kg} / \mathrm{m}^{2}\right)$. However, our findings showed significant associations between macronutrient intake and blood lipids mainly in the high-adiposity groups, which initially would be in contrast to previous literature.

There were several limitations to our findings. Due to the cross-sectional nature of the study, we cannot determine causality. Hormonal changes during the menstrual cycle may influence serum lipid concentrations; however, blood samples were not taken at the consistent time of the menstrual cycle to account for that factor. Although the self-administered 
24-HDR used to assess dietary intake is subject to measurement errors as occurs with other self-reporting methods, it has been shown to be appropriate to collect detailed dietary data in adolescents ${ }^{(12,13)}$. Collection of dietary data for more than $2 \mathrm{~d}$ would have been desirable to compensate for day-to-day variability ${ }^{(48)}$; nevertheless, dietary information was corrected for within-person variability to partially mitigate such limitation ${ }^{(49)}$. Additionally, our sample included underreporters; however, results did not change when they were withdrawn from the analyses. The BLS food composition table was used to ensure that all countries used the same food composition data (obtained via the same definitions and analytical methods), though it might also represent a limitation as not all country-specific recipes and foods could be found in this German food composition table. However, recipes were generated to calculate nutrient intakes for those particular recipes. The sex- and age-specific medianbased cut-offs used are sample specific and, therefore, limits their comparability with other studies. Also, adolescents included in the present study cannot be considered a true representative sample due to differences in age, weight and height compared with the original HELENA sample.

The present study has several strengths. Blood samples were collected following a standardised methodology and transported to a centralised laboratory in order to ensure the viability and stability of the samples ${ }^{(22)}$. Fieldworkers were trained and a manual of operation was developed to guarantee good clinical practice ${ }^{(22)}$. The present results were adjusted for multiple testing by the Bonferroni method, which is considered as a very conservative method.

In conclusion, the present study showed the associations between energy-adjusted macronutrient intake and serum lipid profile in adolescents. Fat intake was related to a better serum lipid profile while carbohydrate intake was observed to be associated with an adverse lipid profile. It is noteworthy that these associations differed according to body fat status and were consistent across the obesity definitions used. These findings emphasise the importance of considering body fat status when developing strategies to prevent the risk of CVD among adolescents since serum lipids and obesity are the major markers of CVD risk. More research is needed, preferably with a longitudinal design, to confirm these findings.

\section{Acknowledgements}

The authors gratefully acknowledge all participating children and adolescents, and their parents and teachers for their collaboration. The authors thank Petra Pickert and Anke Carstensen for their contribution to the laboratory work.

The authors take the sole responsibility for the content of this article. The content of this article reflects the views of the authors only, and the European Community is not liable for any use that may be made of the information contained therein. The HELENA study was financially supported by the European Community Sixth RTD Framework Programme (contract FOOD-CT-2005007034). The European Community had no role in the design or analysis of the study or in the writing of this article. The present study was also supported by the Aragón's Regional
Government (SBS, grant no. B079/08), by a grant from the Spanish Ministry of Science and Innovation (grants no. JCI-2010-07055 and AP2008-03806) and by the European Regional Development Fund (MICINN-FEDER).

The authors' contributions were as follows: L. A. M., F. G., A. K., Y. M., D. M., K. W. and M. S. participated in the conception and design of the study; S. B.-S., I. H., M. C.-G., G. P., C. B., R. R., K. V., M. S., L. L. and S. G.-M. conducted the research and collected the data; S. B.-S. wrote the manuscript, analysed the data and generated the figures; T. M., I. H., I. L. and L. A. M. participated in the interpretation of the data; S. B.-S., T. M., I. H., I. L., M. C.-G., G. P., C. B., D. M., R. R., K. W., F. G., A. K., Y. M., K. V., M. S., L. L., S. G.-M. and L. A. M. critically reviewed the manuscript. All authors read and approved the final manuscript.

There are no conflicts of interest.

\section{References}

1. Saland JM (2007) Update on the metabolic syndrome in children. Curr Opin Pediatr 19, 183-191.

2. Nicklas TA, von Duvillard SP \& Berenson GS (2002) Tracking of serum lipids and lipoproteins from childhood to dyslipidemia in adults: the Bogalusa Heart Study. Int J Sports Med 23, Suppl. 1, S39-S43.

3. Flock MR, Green MH \& Kris-Etherton PM (2011) Effects of adiposity on plasma lipid response to reductions in dietary saturated fatty acids and cholesterol. Adv Nutr 2, 261-274.

4. Mozaffarian D, Rimm EB \& Herrington DM (2004) Dietary fats, carbohydrate, and progression of coronary atherosclerosis in postmenopausal women. Am J Clin Nutr 80, 1175-1184.

5. Ma Y, Li Y, Chiriboga DE, et al. (2006) Association between carbohydrate intake and serum lipids. J Am Coll Nutr 25, 155-163.

6. Appel LJ, Sacks FM, Carey VJ, et al. (2005) Effects of protein, monounsaturated fat, and carbohydrate intake on blood pressure and serum lipids: results of the OmniHeart randomized trial. JAMA 294, 2455-2464.

7. Siri-Tarino PW, Sun Q, Hu FB, et al. (2010) Meta-analysis of prospective cohort studies evaluating the association of saturated fat with cardiovascular disease. Am J Clin Nutr 91, 535-546.

8. Bertheke Post G, de Vente W, Kemper HC, et al. (2001) Longitudinal trends in and tracking of energy and nutrient intake over 20 years in a Dutch cohort of men and women between 13 and 33 years of age: The Amsterdam Growth and Health Longitudinal Study. Br J Nutr 85, 375-385.

9. Moreno LA, De Henauw S, Gonzalez-Gross M, et al. (2008) Design and implementation of the Healthy Lifestyle in Europe by Nutrition in Adolescence Cross-Sectional Study. Int J Obes (Lond) 32, Suppl. 5, S4-S11.

10. Moreno LA, Gonzalez-Gross M, Kersting M, et al. (2008) Assessing, understanding and modifying nutritional status, eating habits and physical activity in European adolescents: the HELENA (Healthy Lifestyle in Europe by Nutrition in Adolescence) Study. Public Health Nutr 11, 288-299.

11. Beghin L, Castera M, Manios Y, et al. (2008) Quality assurance of ethical issues and regulatory aspects relating to good clinical practices in the HELENA Cross-Sectional Study. Int J Obes (Lond) 32, Suppl. 5, S12-S18.

12. Vereecken CA, Covents M, Matthys C, et al. (2005) Young adolescents' nutrition assessment on computer (YANA-C). Eur J Clin Nutr 59, 658-667. 
13. Vereecken CA, Covents M, Sichert-Hellert W, et al. (2008) Development and evaluation of a self-administered computerized 24-h dietary recall method for adolescents in Europe. Int J Obes (Lond) 32, Suppl. 5, S26-S34.

14. Dehne LI, Klemm C, Henseler G, et al. (1999) The German Food Code and Nutrient Data Base (BLS II.2). Eur J Epidemiol 15, 355-359.

15. Harttig U, Haubrock J, Knuppel S, et al. (2011) The MSM program: web-based statistics package for estimating usual dietary intake using the Multiple Source Method. Eur J Clin Nutr 65, Suppl. 1, S87-S91.

16. Willett WC, Howe GR \& Kushi LH (1997) Adjustment for total energy intake in epidemiologic studies. Am J Clin Nutr $\mathbf{6 5}$ 1220S-1228S, discussion 1229S-1231S.

17. Connor SL, Gustafson JR, Artaud-Wild SM, et al. (1989) The cholesterol-saturated fat index for coronary prevention: background, use, and a comprehensive table of foods. $J \mathrm{Am}$ Diet Assoc 89, 807-816.

18. Vyncke K, Cruz Fernandez E, Fajo-Pascual M, et al. (2013) Validation of the Diet Quality Index for Adolescents by comparison with biomarkers, nutrient and food intakes: the HELENA study. Br J Nutr 109, 2067-2078.

19. Nagy E, Vicente-Rodriguez G, Manios Y, et al. (2008) Harmonization process and reliability assessment of anthropometric measurements in a multicenter study in adolescents. Int $J$ Obes (Lond) 32, Suppl. 5, S58-S65.

20. Cole TJ, Bellizzi MC, Flegal KM, et al. (2000) Establishing a standard definition for child overweight and obesity worldwide: international survey. BMJ 320, 1240-1243.

21. Cole TJ, Flegal KM, Nicholls D, et al. (2007) Body mass index cut offs to define thinness in children and adolescents: international survey. BMJ 335, 194.

22. Gonzalez-Gross M, Breidenassel C, Gomez-Martinez S, et al. (2008) Sampling and processing of fresh blood samples within a European multicenter nutritional study: evaluation of biomarker stability during transport and storage. Int $J$ Obes (Lond) 32, Suppl. 5, S66-S75.

23. Rey-Lopez JP, Ruiz JR, Ortega FB, et al. (2012) Reliability and validity of a screen time-based sedentary behaviour questionnaire for adolescents: the HELENA study. Eur $J$ Public Health 22, 373-377.

24. Ruiz JR, Ortega FB, Martinez-Gomez D, et al. (2011) Objectively measured physical activity and sedentary time in European adolescents: the HELENA study. Am J Epidemiol 174, 173-184

25. Ekelund U, Sardinha LB, Anderssen SA, et al. (2004) Associations between objectively assessed physical activity and indicators of body fatness in 9- to 10-y-old European children: a population-based study from 4 distinct regions in Europe (the European Youth Heart Study). Am J Clin Nutr 80, 584-590.

26. Spinneker A, Egert S, Gonzalez-Gross M, et al. (2012) Lipid, lipoprotein and apolipoprotein profiles in European adolescents and its associations with gender, biological maturity and body fat - the HELENA Study. Eur J Clin Nutr 66, 727-735

27. Ruottinen S, Ronnemaa T, Niinikoski H, et al. (2009) Carbohydrate intake, serum lipids and apolipoprotein E phenotype show association in children. Acta Paediatr 98, $1667-1673$.

28. Oda H (2006) Functions of sulfur-containing amino acids in lipid metabolism. J Nutr 136, 1666S-1669S.

29. Potter SM (1996) Soy protein and serum lipids. Curr Opin Lipidol 7, 260-264.

30. Lichtenstein AH (2006) Thematic review series: patientoriented research. Dietary fat, carbohydrate, and protein: effects on plasma lipoprotein patterns. I Lipid Res 47, $1661-1667$

31. Jakobsen MU, O'Reilly EJ, Heitmann BL, et al. (2009) Major types of dietary fat and risk of coronary heart disease: a pooled analysis of 11 cohort studies. Am J Clin Nutr 89, $1425-1432$.

32. Berglund L, Lefevre M, Ginsberg HN, et al. (2007) Comparison of monounsaturated fat with carbohydrates as a replacement for saturated fat in subjects with a high metabolic risk profile: studies in the fasting and postprandial states. $\mathrm{Am} \mathrm{J}$ Clin Nutr 86, 1611-1620.

33. Lichtenstein AH, Matthan NR, Jalbert SM, et al. (2006) Novel soybean oils with different fatty acid profiles alter cardiovascular disease risk factors in moderately hyperlipidemic subjects. Am J Clin Nutr 84, 497-504.

34. Gillingham LG, Harris-Janz S \& Jones PJ (2011) Dietary monounsaturated fatty acids are protective against metabolic syndrome and cardiovascular disease risk factors. Lipids $\mathbf{4 6}$, 209-228.

35. Schwingshackl L \& Hoffmann GJ (2013) Comparison of effects of long-term low-fat vs high-fat diets on blood lipid levels in overweight or obese patients: a systematic review and meta-analysis. J Acad Nutr Diet 113, 1640-1661.

36. Lyu LC, Yeh CY, Lichtenstein AH, et al. (2001) Association of sex, adiposity, and diet with HDL subclasses in middle-aged Chinese. Am J Clin Nutr 74, 64-71.

37. Cobb M, Greenspan J, Timmons M, et al. (1993) Gender differences in lipoprotein responses to diet. Ann Nutr Metab 37, 225-236.

38. Walden CE, Retzlaff BM, Buck BL, et al. (2000) Differential effect of National Cholesterol Education Program (NCEP) Step II diet on HDL cholesterol, its subfractions, and apoprotein A-I levels in hypercholesterolemic women and men after 1 year: the beFIT Study. Arterioscler Thromb Vasc Biol 20, $1580-1587$.

39. Li Z, Otvos JD, Lamon-Fava S, et al. (2003) Men and women differ in lipoprotein response to dietary saturated fat and cholesterol restriction. J Nutr 133, 3428-3433.

40. Lichtenstein AH, Ausman LM, Jalbert SM, et al. (1999) Effects of different forms of dietary hydrogenated fats on serum lipoprotein cholesterol levels. $N$ Engl J Med 340, $1933-1940$.

41. Kromhout D, Geleijnse JM, Menotti A, et al. (2011) The confusion about dietary fatty acids recommendations for CHD prevention. Br J Nutr 106, 627-632.

42. Mensink RP, Zock PL, Kester AD, et al. (2003) Effects of dietary fatty acids and carbohydrates on the ratio of serum total to HDL cholesterol and on serum lipids and apolipoproteins: a meta-analysis of 60 controlled trials. Am J Clin Nutr 77, 1146-1155.

43. Samuelson G, Bratteby LE, Mohsen R, et al. (2001) Dietary fat intake in healthy adolescents: inverse relationships between the estimated intake of saturated fatty acids and serum cholesterol. Br J Nutr 85, 333-341.

44. Micha R \& Mozaffarian D (2010) Saturated fat and cardiometabolic risk factors, coronary heart disease, stroke, and diabetes: a fresh look at the evidence. Lipids $\mathbf{4 5}$, 893-905.

45. Rice BH, Cifelli CJ, Pikosky MA, et al. (2011) Dairy components and risk factors for cardiometabolic syndrome: recent evidence and opportunities for future research. Adv Nutr 2, 396-407.

46. Clifton PM, Abbey M, Noakes M, et al. (1995) Body fat distribution is a determinant of the high-density lipoprotein response to dietary fat and cholesterol in women. Arterioscler Thromb Vasc Biol 15, 1070-1078. 
47. Denke MA, Adams-Huet B \& Nguyen AT (2000) Individual cholesterol variation in response to a margarine- or butterbased diet: a study in families. JAMA 284, 2740-2747.

48. Thompson F \& Subar A (2008) Dietary assessment methodology. In Nutrition in the Prevention and Treatment of Disease, 2nd ed., pp. 3-39 [A Coulston and C Boushey, editors]. Diego, CA: Elsevier Academic Press.

49. Dodd KW, Guenther PM, Freedman LS, et al. (2006) Statistical methods for estimating usual intake of nutrients and foods: a review of the theory. J Am Diet Assoc 106, $1640-1650$

\section{APPENDIX: HELENA Study Group}

Co-ordinator: L. A. Moreno

Core Group members: L. A. Moreno, F. Gottrand, S. De Henauw, M. González-Gross, C. Gilbert

Steering Committee: A. Kafatos (President), L. A. Moreno, C. Libersa, S. De Henauw, J. Sánchez, F. Gottrand, M. Kersting, M. Sjöstrom, D. Molnár, M. González-Gross, J. Dallongeville, C. Gilbert, G. Hall, L. Maes, L. Scalfi

Project Manager: P. Meléndez

Universidad de Zaragoza (Spain): L. A. Moreno, J. Fleta, J. A. Casajús, G. Rodríguez, C. Tomás, M. I. Mesana, G. Vicente-Rodríguez, A. Villarroya, C. M. Gil, I. Ara, J. Revenga, C. Lachen, J. Fernández-Alvira, G. Bueno, A. Lázaro, O. Bueno, J. F. León, J. Ma. Garagorri, M. Bueno, J. P. Rey López, I. Iglesia, P. Velasco, S. Bel-Serrat, L. Gracia-Marco, T. Mouratidou, D. Jiménez-Pavón

Consejo Superior de Investigaciones Científicas (Spain): A. Marcos, J. Wärnberg, E. Nova, S. Gómez-Martínez, E. Ligia Díaz, J. Romeo, A. Veses, M. Angeles Puertollano, B. Zapatera, T. Pozo

Université de Lille 2 (France): L. Beghin, C. Libersa, F. Gottrand, C. Iliescu, J. Von Berlepsch

Research Institute of Child Nutrition Dortmund, Rheinische Friedrich-Wilhelms-Universität Bonn (Germany): M. Kersting, W. Sichert-Hellert, E. Koeppen

Pécsi Tudományegyetem (University of Pécs) (Hungary): D. Molnar, E. Erhardt, K. Csernus, K. Török, S. Bokor, Mrs Angster, E. Nagy, O. Kovács, J. Répasi

University of Crete School of Medicine (Greece): A. Kafatos, C. Codrington, M. Plada, A. Papadaki, K. Sarri, A. Viskadourou,

C. Hatzis, M. Kiriakakis, G. Tsibinos, C. Vardavas, M. Sbokos,

E. Protoyeraki, M. Fasoulaki

Institut für Ernährungs- und Lebensmittelwissenschaften Ernäbrungphysiologie. Rheinische Friedrich Wilhelms Universität (Germany): P. Stehle, K. Pietrzik, M. González-Gross, C. Breidenassel, A. Spinneker, J. Al-Tahan, M. Segoviano, A. Berchtold, C. Bierschbach, E. Blatzheim, A. Schuch, P. Pickert

University of Granada (Spain): M. J. Castillo, A. Gutiérrez, F. B. Ortega, J. R. Ruiz, E. G. Artero, V. España, D. JiménezPavón, P. Chillón, C. Sánchez-Muñoz, M. Cuenca
Istituto Nazionale di Ricerca per gli Alimenti e la Nutrizione (Italy): D. Arcella, E. Azzini, E. Barrison, N. Bevilacqua, P. Buonocore, G. Catasta, L. Censi, D. Ciarapica, P. D'Acapito, M. Ferrari, M. Galfo, C. Le Donne, C. Leclercq, G. Maiani, B. Mauro, L. Mistura, A. Pasquali, R. Piccinelli, A. Polito, R. Spada, S. Sette, M. Zaccaria

University of Napoli "Federico II" Dept of Food Science (Italy): L. Scalfi, P. Vitaglione, C. Montagnese

Ghent University (Belgium): I. De Bourdeaudhuij, S. De Henauw, T. De Vriendt, L. Maes, C. Matthys, C. Vereecken, M. de Maeyer, C. Ottevaere, I. Huybrechts

Medical University of Vienna (Austria): K. Widhalm, K. Phillipp, S. Dietrich, B. Kubelka, M. Boriss-Riedl

Harokopio University (Greece): Y. Manios, E. Grammatikaki, Z. Bouloubasi, T. Louisa Cook, S. Eleutheriou, O. Consta, G. Moschonis, I. Katsaroli, G. Kraniou, S. Papoutsou, D. Keke, I. Petraki, E. Bellou, S. Tanagra, K. Kallianoti, D. Argyropoulou, K. Kondaki, S. Tsikrika, C. Karaiskos

Institut Pasteur de Lille (France): J. Dallongeville, A. Meirhaeghe

Karolinska Institutet (Sweden): M. Sjöström, J. Ruiz, F. B. Ortega, M. Hagströmer, L. Hallström, E. Patterson, L. Kwak, J. Wärnberg, N. Rizzo, A. Hurtig Wennlöf

Asociación de Investigación de la Industria Agroalimentaria (Spain): J. Sánchez-Molero, E. Picó, M. Navarro, B. Viadel, J. E. Carreres, G. Merino, R. Sanjuán, M. Lorente, M. J. Sánchez, S. Castelló

Campden BRI (United Kingdom): C. Gilbert, S. Thomas, E. Allchurch, P. Burguess

SIK - Institutet foer Livsmedel och Bioteknik (Sweden): G. Hall, A. Astrom, A. Sverkén, A. Broberg

Meurice Recherche E Development asbl (Belgium): A. Masson, C. Lehoux, P. Brabant, P. Pate, L. Fontaine

Campden and Chorleywood Food Development Institute (Hungary): A. Sebok, T. Kuti, A. Hegyi

Productos Aditivos SA (Spain): C. Maldonado, A. Llorente

Cárnicas Serrano SL (Spain): E. García

Cederroth International $A B$ (Sweden): H. von Fircks, M. Lilja Hallberg, M. Messerer

Lantmännen Food RED (Sweden): M. Larsson, H. Fredriksson, V. Adamsson, I. Börjesson

European Food Information Council (Belgium): L. Fernández, L. Smillie, J. Wills

Universidad Politécnica de Madrid (Spain): M. GonzálezGross, J. Valtueña, U. Albers, R. Pedrero, A. Meléndez, P. J. Benito, D. Cañada, D. Jiménez-Pavón, A. Urzanqui, J. C. Ortiz, F. Fuentes, J. J. Gómez Lorente, R. Mardía Torres, P. Navarro 